\title{
Debate
}

\section{Buying human kidneys: autonomy, commodity and power}

\author{
Bob Brecher Brighton Polytechnic
}

\section{Author's abstract}

Buttle's reply to my objections to buying kidneys is helpful but unconvincing in two respects. Doing something freely leaves quite open the possibility that one is thereby making a commodity of a person; and the effects of institutionalising such a practice is itself a matter for concern. And while his emphasis on 'power' is important, the concept is hardly less problematic than 'commodification'.

Buttle's riposte to my attempt to focus on the buyer rather than the seller in thinking about 'the kidney trade' is most welcome, pushing the debate as it does in exactly the right direction: just what is wrong with buying a human kidney? However, although I agree that I do not answer the question (indicating only 'the briefest outline of how [such] an argument might look'; that 'commodification' is far from unproblematic; and that my cavalier way with state intervention poses real dangers), I remain unconvinced of his two central objections.

First, the fact that: 'Individuals may freely choose to engage in these practices, so that they may express a person's autonomy ...' (page 97) does not imply that what people do does not constitute commodification, autonomy notwithstanding. If I freely choose to sell myself into slavery, then, whatever one's (Kantian, Millian, or other) view of the role of its infringing my freedom and autonomy were I to be denied the opportunity to go ahead with the transaction, it remains the case that I am making a commodity of myself. An action's being freely chosen does not preclude its being an act of commodification. Indeed, it is partly for this reason that I am inclined to think that if people have 'a lack of power ... to control their

\section{Key words}

Sale of organs; kidneys. lives' (page 98) then to that extent they cannot 'freely choose to engage in' certain jobs. Such freedom is metaphysical only (if even that): it is in practice constrained by just that inequality of power, and economic power in particular, that Buttle rightly emphasises.

The central issue is this: what, if anything, is wrong with making a commodity of a person? A lengthy article would hardly suffice. All I shall say here, however, is that it is certainly not - in my view - a matter simply of Kantian respect for individual autonomy, since, as Buttle rightly points out (page 97) I am quite prepared to undermine such individual autonomy: one person's freedom to buy is another's need to sell. And Buttle's emphasis on power is, I suspect, part of the story - but not the whole, since one might ask of the (unequal) wielding of power just the same question as of the commodification of people: what, exactly, is wrong with it? The trouble is that 'power' is so broad a notion that one has to spell out sets of conditions regarding its use, sort and circumstances if it is not to collapse into a blanket thrown over these questions. And that is at least as difficult a task as convincingly criticising the commodification of people - though I agree that that remains to be done, if it can be.

Secondly, Buttle and I disagree about the importance of the institutional impact of particular practices on the possibility of developing a moral/ political/cultural climate within which the redistribution which we agree is desirable might actually occur. In my view, but not, I think, in Buttle's, the institutionalisation of buying human kidneys would be a further reinforcement of the present, anti-redistributivist climate, and thus be not the least of what is wrong with (further) commodifying people in this way. But that is another long story.

Bob Brecher is Principal Lecturer in Philosophy in the Humanities Department of Brighton Polytechnic. 